\title{
El exilio republicano español en México: Memoria e identidad
}

\author{
The Spanish Republican exile in Mexico: \\ Memory and Identity \\ O exílio republicano espanhol no México: \\ memória e identidade
}

\author{
Guiomar Acevedo-López \\ Profesora investigadora \\ Universidad Nacional Autónoma \\ México
}

Recibido:28/11/2019 - Aceptado:15/01/2020

\begin{abstract}
Resumen
El exilio republicano español en México, el tema de la memoria y su transmisión ha sido central en la historiografía, tanto si se plantea dicho exilio como comunidad o como fenómeno cultural. El fenómeno contó con una férrea "voluntad de memoria" que preservó simbólicamente la identidad de la comunidad (Lida, 2001) y los recuerdos fueron transmitidos a los descendientes en forma de "memorias heredadas" (Acevedo, 2011) que han permitido cierta continuidad identitaria transgeneracional. Por otra parte, el continuado uso del apelativo refugiado en una comunidad que no se encontraba sujeta a los límites legales de tal término, sugiere que los usos de dicho apelativo o categoría remiten también a cuestiones de identidad y memoria. Una revisión paralela de la construcción de narrativas identitarias en el exilio, así como de la propia historia de la categoría, podría arrojar luz a los intricados procesos de consolidación de la memoria colectiva y la identidad del exilio republicano español en México.
\end{abstract}

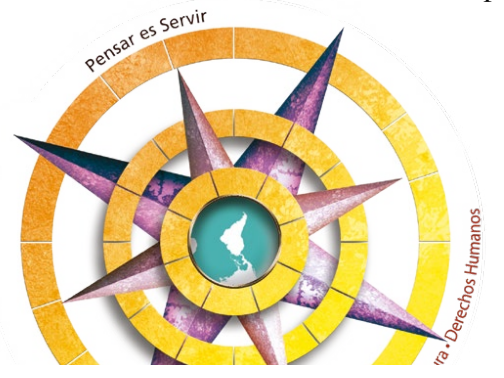

Palabras clave: Exilio, memoria, identidad, refugiados, Guerra Civil Española, pensamiento latinoamericano. 


\begin{abstract}
The Spanish Republican Exile in Mexico, the issue of memory and its transmission has been central to historiography, whether the exile is considered as a community or as a cultural phenomenon. The phenomenon had a strong "will to remember" that symbolically preserved the identity of the community (Lida, 2001) and the memories were transmitted to the descendants in the form of "inherited memories" (Acevedo, 2011) that have allowed for a certain trans-generational identity continuity. On the other hand, the continued use of the appellation refugee(s) in a community that was not subject to the legal limits of that term suggests that the uses of that appellation or category also refer to questions of identity and memory. A parallel review of the construction of identity narratives in exile, as well as of the history of the category itself, could shed light on the intricate processes of consolidation of the collective memory and identity of the Spanish Republican Exile in Mexico
\end{abstract}

Keywords Exile, memory, identity, refugees, Spanish Civil War, Latin American thought

Resumo

O Exílio Republicano Espanhol no México, a questão da memória e da sua transmissão tem sido central para a historiografia, quer o exílio seja considerado como uma comunidade ou como um fenómeno cultural. O fenómeno teve uma forte "vontade de lembrar" que preservou simbolicamente a identidade da comunidade (Lida, 2001) e as memórias foram transmitidas aos descendentes sob a forma de "memórias herdadas" (Acevedo, 2011) que permitiram uma certa continuidade de identidade transgeracional. Por outro lado, o uso continuado da denominação refugiado(s) numa comunidade que não estava sujeita aos limites legais desse termo sugere que os usos dessa denominação ou categoria também se referem a questões de identidade e memória. Uma revisão paralela da construção de narrativas de identidade no exílio, bem como da história da própria categoria, poderia lançar luz sobre os intrincados processos de consolidação da memória colectiva e da identidade do Exílio Republicano Espanhol no México.

Palavras chave: Exílio, memória, identidade, refugiados, Guerra Civil Espanhola, pensamento latino-americano

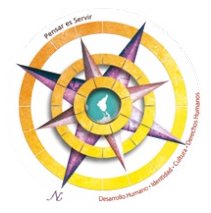


Para comprender al exilio republicano español en México, ya sea como comunidad o como fenómeno cultural, el tema de la memoria, así como su transmisión y conservación, ha sido central en la historiografía. De igual manera, los estudios sobre este exilio han indagado respecto a diversas cuestiones sobre identidad. Se ha argumentado que el exilio republicano español en México como colectivo hizo grandes esfuerzos de conservación de la memoria, los cuales preservaron simbólicamente la identidad de la comunidad. Concretamente, la Dra. Clara Lida ha propuesto que el exilio contó con una férrea "voluntad de memoria" manifiesta, ya sea en los recuerdos individuales escritos o en las instituciones de la colectividad que preservaron, simbólicamente, la identidad social y cultural de la comunidad. ${ }^{1}$

Además, esta voluntad de memoria de los propios exiliados republicanos fue, a su vez, transmitida, de la mano de cada recuerdo compartido, a sus descendientes, en forma de "memorias heredadas", y ha permitido cierta continuidad

1 Cf. Clara Lida: "Voluntad de memoria. Los exilios hispánicos en México en siglo XX", en Actas XIV Congreso Asociación Internacional de Hispanistas: Nueva York 16-21 Julio 2001, Vol. I, España, 2004, pp. 311-324. identitaria transgeneracional a lo largo de ocho décadas. ${ }^{2}$

Las memorias del exilio republicano español cobran su mayor relevancia frente a la censura y el revisionismo histórico de la dictadura franquista, así como frente a la desmemoria impuesta por el pacto de silencio de la transición materializado en la Ley de Amnistía de 1977, pues pueden ser vistas como una forma de resistencia -política, social y cultural- frente a la imposición del olvido sistematizado desde el Estado español. Sin embargo, esto plantea la necesidad de preguntarnos: ¿qué han recordado los exiliados y cuál es el ethos de dichas memorias?

Las respuestas a estas preguntas se encuentran, a su vez, estrechamente relacionadas con la cuestión de la conformación identitaria del exilio español en México.

En el contexto global, los refugiados se han convertido en actores clave para la construcción de discursos que buscan nuevas formas de pensar los problemas de identidad y de representación, tanto del sujeto o comunidad, como del

2 Cf. Acevedo López, Guiomar, Entre memoria y olvido: Ochenta años del pasado contemporáneo español, Limusa-Morados, México, 2011, pp. 96-103. 
pasado, pues elaboran narrativas que recrean y reconfiguran su tierra de origen desde el desplazamiento y la distancia geográfica y cronológica, asumen esta distancia como el eje mismo de su enunciación discursiva. Analizar estos procesos permite comprender la asimilación de la des-locación y ayudan a comprender la naturaleza discontinua y fracturada de la memoria contemporánea. ${ }^{3}$

Además, en la medida en que la situación y estatus de los refugiados continúa siendo un conflicto actual de dimensiones internacionales, los estudios de refugiados ofrecen la posibilidad de revisar casos concretos para indagar respecto a las diversas prácticas implementadas para tratar este conflicto social y humano.

Ahora bien, al examinar la cuestión de la conformación identitaria en el exilio español en México, hay dos vertientes que resulta interesante examinar vis-à-vis: el exilio como un común denominador identitario que comparte la comunidad exiliada y el exilio como un fenómeno cultural mexicano.

Para comprender la primera vertiente, debemos detenernos en el análisis

3 Cf. Linda Anderson, "Diaspora: Introduction", en Rossington, Michael y Anne Whitehead (eds.), Theories of Memory. A Reader, Johns Hopkins University Press, Baltimor, 2007, p. 274. de la producción editorial que el propio exilio generó para explicarse su condición de comunidad desplazada por motivos políticos y, por lo tanto, no podemos pasar por alto el término "transterrado", acuñado por el intelectual exiliado José Gaos en la década de los cuarenta; y la posterior crítica que, de este neologismo, hizo el filósofo, también exiliado, Adolfo Sánchez Vázquez.

En palabras del propio Sánchez Vázquez:

El exilio cobra un significado especial por encima del desgarrón que entraña, pues se trata de un encuentro que es, a la vez, una recuperación. Lo perdido allá, se recupera aquí. El término "transterrado", que Gaos acuña al final de la década de los cuarenta, aunque sólo adquiere una creciente carta de ciudadanía después, expresa claramente esta concepción. El exiliado no es tanto el hombre que se ha quedado sin tierra -desterrado o aterrado-, sino el que, transplantado a otra, encuentra en ella la tierra perdida. (Sánchez, 1997, p. 125)

Aun así, mientras Gaos apuntaba con su término "transterrados" a la posibilidad de adaptación a la tierra de acogida -adaptación posible gracias a una lengua y un pasado comunes-, Sánchez Vázquez busca enfatizar el

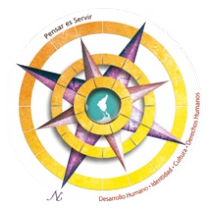


camino que lleva al exiliado a poder transplantarse en México y convertirse en un transterrado. Este recorrido se dividía en tres etapas: primero el exiliado es un aterrado, en el doble sentido de la palabra, es decir, un ser humano sin tierra y atenazado por el miedo; con el tiempo, el aterrado será consciente del desgarrón de lo perdido, siendo entonces un desterrado; y solo cuando el desterrado verdaderamente ha echado raíces en el país adoptivo, es cuando puede ser considerado un transterrado. (1997)

Así pues, para Sánchez Vázquez, el término transterrado hará referencia a lo encontrado por encima de lo perdido; lo cual contribuyó a solidificar el vínculo con México como una parte integral de la identidad del exiliado.

En este sentido, otro matiz importante a tomarse en cuenta para la búsqueda de un común denominador identitario del exilio es la clara distinción entre el refugiado y el español de la 'vieja colonia'. En palabras de Juan Bautista Climent:

A los [republicanos] recién llegados se les plantea un fenómeno típico de la emigración española en México. El encuentro con una denominación y un concepto del emigrante español que se proyecta como espinosa herencia del régimen colonial, que pervive como un resquemor del movimiento de independencia frente a España, el encuentro con el calificativo de 'gachupín'. 4

El gachupín era -y sigue siendo- el otro español en México, el que había llegado a "hacer la América" y era tradicionalmente visto y tratado con desconfianza. Esta desconfianza responde a una larga historia de xenofilias y xenofobias consolidadas a lo largo de quinientos años. ${ }^{5}$

Por estas razones, era fundamental que el propio exilio republicano enfatizara sus diferencias con los gachupines de la llamada 'vieja colonia' estableciendo una clara distinción entre ambos grupos; por lo que se debe revisar la construcción discursiva de la categoría refugiado frente a la de migrante -gachupín-, pues ambas categorías se han construido de manera paralela y mantienen una gran vigencia actual. Visto así, ambas categorías pueden ser entendidas como "dispositivos", entendiendo a los mismos a partir de la episteme foucaultiana que los explica como

4 Climent Beltrán, Juan Bautista, Crónicas de Valencia. Escritos desde el exilio, Generalitat Valenciana, Conselleria de Cultura, Educació i Ciéncia, Valencia, 1992, p. 133.

5 Cf. Lida, Clara, Inmigración y exilio. Reflexiones sobre el caso español, Siglo XXI-El Colegio de México, México, 1997, pp. 16-22. 
prácticas discursivas que producen formas de subjetividad. ${ }^{6}$

En este sentido, el apoyo de los intelectuales mexicanos de ideas liberales y la inmersión de los exiliados en la vida cultural del país, apoyando la construcción del nuevo y moderno México de la post-revolución, ayudó a establecer esta distinción entre el refugiado y el gachupín. ${ }^{7}$

Esta inmersión en la vida cultural de México fue variada e incluyó la incorporación de profesores exiliados en las principales universidades del país, la creación de las escuelas del exilio -que, más adelante, serían escuelas mexicanas de pleno derechoy una vasta producción editorial vía la Universidad Nacional Autónoma de México, el Fondo de Cultura Económica, la Editorial Séneca y, posteriormente, Siglo XXI, entre

6 Cf. Foucault, Michel: "El juego de Michel Foucault", en Saber y verdad, Madrid, Ediciones de la Piqueta, 1984, pp. 127-162. Cabe mencionar que el uso del término dispositivo tomará en cuenta las tres vertientes que señala Foucault: 1) el dispositivo como red "es decir, el conjunto heterogéneo que incluye discursos, instituciones, leyes, proposiciones morales, etc.", 2) el dispositivo como la propia naturaleza de esta red y, finalmente, 3) el dispositivo como una especie de formación que en un contexto histórico específico responde a una "urgencia".

7 Cf. Vicente Guarner, "Los exiliados españoles del 39 y el México de ahora”, en Autores varios, El exilio español en México, 1939-1982, FCE, Salvat, México, 1982, p. 706. otras. Además, esta amplia inclusión en la vida cultural mexicana fue lo que terminó por convertir al exilio español en México en un fenómeno cultural propiamente mexicano.

En un homenaje a Adolfo Sánchez Vázquez realizado en 2006 en el marco de la XX Feria Internacional del Libro de Guadalajara, el también filósofo exiliado, Federico Álvarez Arregui, decía de su colega y del propio exilio:

En verdad que somos un fenómeno histórico vital cerrado, que somos supervivientes de algo que se perdió para siempre, pero su memoria, en España, está lejos de cerrarse y, en tanto que memoria, es una herencia inconmovible. Se trata, pues, con respecto a nosotros en México, de una identidad digamos, de ida y vuelta. El exilio llegó a México y, sin dejar de serlo [exilio], fue mexicano. En eso ha sido también Adolfo Sánchez Vázquez un modelo excepcional. Casi sin darse cuenta -sin darnos cuenta-fue una figura indiscutida de la cultura mexicana. ${ }^{8}$

Ahora bien, pese a que un importante número de los trabajos sobre el tema tienden a favorecer el término

8 Federico Álvarez Arregui, "Discurso de D. Federico Álvarez Arregui”, en M. D. Gutiérrez Navas (ed.), Homenaje a Adolfo Sánchez Vázquez, FCE-Junta de Andalucía, Conserjería de la Cultura, Madrid, 2007, p. 44. 
exiliado, su uso cotidiano es mucho menos extenso -y bastante más reciente- que el uso del apelativo refugiado: a lo largo de innumerables páginas de testimonios, memorias, autobiografías y ensayos diversos, nos encontramos con el uso del término "refugiado". Así pues, parece que, al momento de indagar sobre la conformación identitaria de la comunidad del exilio republicano español en México, el uso coloquial del apelativo refugiado no ha sido revisado detenidamente.

Este punto resulta particularmente interesante ya que, desde el punto de vista de las definiciones legales nacionales e internacionales, los españoles republicanos pueden ser considerados refugiados cuando la población civil tuvo que ser evacuada o decidió voluntariamente partir de las zonas de conflicto durante la Guerra Civil; así mismo, pueden considerarse -por el tratamiento legal que recibieron- refugiados en Francia.

Sin embargo, para el sistema jurídico mexicano, los españoles republicanos nunca fueron refugiados, sino que fueron asilados políticos: el hecho mismo de que hayan tenido la posibilidad de acceder a la nacionalidad mexicana desde el primer momento hace que su estatus legal no haya quedado suspendido en el liminal territorio de incertidumbre jurídica al que los refugiados se ven sujetos; por lo que, el uso coloquial del distintivo "refugiados españoles", con el que la propia comunidad de exiliados en México se ha referido a sí misma, apela a una definición más subjetiva y emotiva, que a una legal. Es decir, resulta fundamental comprender las distinciones en los usos del término refugiado para aclarar su significado y encontrar el origen de dichos usos. ${ }^{9}$

Por otra parte, desde el punto de vista de la teoría de la historia, la revisión de la producción historiográfica sobre el tema y el análisis de los discursos históricos que hacen uso de la categoría refugiado para historiar el desplazamiento forzado nos permiten, en primera instancia, comprender tanto la continuidad como los cambios en la historia del desplazamiento forzado, así como

9 Cf. ACNUR, La situación de los refugiados en el mundo. En busca de la solidaridad, Representación de ACNUR en España, Madrid, 2012. Véase también: Claudia Dávila Valdés: "El tratamiento jurídico-administrativo a los refugiados de la guerra civil española en Francia y México: un estudio comparativo", en Secuencia, No. 69, 2007; y Tirado Sánchez, Aránzazu, La política exterior del México Cardenista hacia la Segunda República Española. El caso del exilio republicano en México: ¿cooperación ideológica o interés pragmático?, Tesis Doctoral, Universidad Autónoma de Barcelona, Bellaterra, 2007. 
abrir un debate respecto a los usos de los diversos términos, apelativos o categorías con los que se enmarca la historización del desplazamiento forzado -refugiados, evacuados, exiliados, etc.- y sus implicaciones metodológicas. Además, en segunda instancia, esta revisión historiográfica sobre el desplazamiento forzado permitiría también entender por qué el campo de los estudios sobre refugiados ha sido, erróneamente, considerado ahistórico. ${ }^{10}$

Dicho de otra forma, para discernir los usos del término refugiado como categoría del sujeto en narrativas respecto a la construcción de identidades colectivas desde el desarraigo, se debe tomar en cuenta, en primera instancia, que se trata de una categoría que se ha construido en diversas instancias (comunales, gubernamentales, académicas, etc.) y que, en ocasiones, el uso coloquial del apelativo "refugiado" ha influido en el ámbito académico o político. Además, en segunda instancia, ha de considerarse que los usos de dicha categoría, en el caso concreto de

10 Para profundizar respecto a la crítica a los estudios sobre refugiados y al rechazo a la afirmación de que estos son ahistóricos, véase: Jérôme, Elie: "Histories of Refugee and ForcedMigrationStudies", enFiddian-Qasmiyeh, Elena, et al (eds.), The Oxford Handbook of Refugee and ForcedMigrationStudies, Oxford UniversityPress, Nueva York, 2014, pp. 23-35. los republicanos españoles, tienen su punto de partida en la propia Guerra Civil Española con los desplazamientos forzados de población -internos y externos-que esta suscitó.

Es decir, quizá resulta posible afirmar que la conformación identitaria del exilio republicano español, como una comunidad desplazada, no fue un proceso que inició en 1939 y de manera independiente a la Guerra Civil, sino que se trató de un proceso iniciado con la propia Guerra y en ella.

En este sentido, un estudio detallado del desplazamiento forzado durante la Guerra Civil Española, que permita conocer los matices de diferenciación entre los usos de los términos evacuados, refugiados, evadidos, etc., permitiría dilucidar la carga, tanto política como afectiva, de cada apelativo, para, a su vez, comprender sus significados en tanto apelativos que hacen referencia, no solo a procesos de desplazamiento y pérdida, sino de pertenencia.

Así pues, quizá el continuado uso del apelativo refugiados por parte de la comunidad del exilio republicano español en México pueda vincularse a varios fenómenos interrelacionados: la solidaridad a la que el término invoca -particularmente importante, como veíamos antes, de cara a

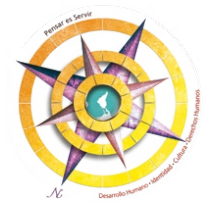


la necesidad de diferenciarse de los 'gachupines'-, el anclaje que dicho apelativo tiene con la memoria de la guerra, en general, y con la memoria de las campañas de solidaridad con los refugiados y evacuados de la guerra, en particular; y, por último, la voluntad de transmisión y conservación de la memoria colectiva del propio exilio republicano español.

Aquí es importante abrir un paréntesis para hacer hincapié en un hecho poco estudiado: revisando la vasta producción de campañas -vía carteles, panfletos e, inclusive, leyes- de solidaridad con los evacuados y refugiados de la guerra, que desarrolló e implementó el Gobierno de la República Española durante la Guerra Civil, podemos constatar algunas de las figuras que, más adelante, tendrían un importante peso para la "cultura del exilio" en México y, por lo tanto, para la construcción de narrativas sobre identidad y memoria del exilio republicano español en México, fueron precisamente quienes diseñaron y ejecutaron, no solo dichas campañas de solidaridad con los refugiados durante la Guerra, sino también los mecanismos oficiales para atender el grave problema de desplazamiento forzado que había desencadenado el conflicto bélico.
Tal es el caso de, por ejemplo, Wenceslao Roces y María Zambrano, el primero, director general de Primera Enseñanza y, por lo tanto, encargado del Consejo Nacional de la Infancia Evacuada; y, la segunda, encargada de la Sección de Propaganda de dicho Consejo, cuyo objetivo era "la organización, dirección, régimen pedagógico y sostenimiento de residencias para los niños evacuados, tanto en España como en otros países". ${ }^{11}$

Roces, en concreto, escribió sobre su condición de español refugiado "renacido mexicano", lo siguiente:

Sea cual sea el color de mis papeles, yo soy un mexicano sin dejar por ello de ser español. Y aún diría que yo soy más acendradamente aquello por ser muy honda y arraigadamente esto ... . Yo no soy un español cualquiera -y todos me parecen respetables-, sino un español refugiado, ante quien las puertas de México se abrieron, creo yo, por una conducta, por una trayectoria y por la natural suposición -sin compromiso alguno, pues nadie, ni yo, y esto es lo hermoso, hemos jurado voto alguno, al venir, ni firmado ningún Libro de Capitulaciones- de que, bajo el cielo de una nueva patria, no seríamos desleales a nuestro linaje.

11 Cf. Gaceta de la República, 28 de agosto de $1937, \mathrm{~N}^{\circ} 240$, p. 827. 
Y lo menos que, como español renacido mexicano, sin perder la primigenia condición, puede uno hacer por la patria de adopción, sin sentirse en modo alguno huérfano de la nacencia y la conciencia, es compartir sus luchas, sus problemas y sus afanes. ${ }^{12}$

María Zambrano, por su parte, encuentra en el estadio refugiado una sentimentalidad que nos recuerda el carácter afectivo de la memoria; $\mathrm{y}$ hace referencia, tanto al recuerdo del lugar perdido, como al lugar en el que fuese acogido. De esta forma, la filósofa marca una clara distinción entre refugiado y desterrado:

Al propiamente refugiado, al únicamente refugiado, el destierro no le absorbe, alguna ráfaga de sentimiento, o más bien de sentimentalidad que le hace asomar lágrimas a los ojos, un consuelo en la debilidad y hasta una especia de ofrenda de aplacatoria a los Lares que a medida que abandona se jura mantener en alto

12 A.G.G.C., Wenceslao Roces "Pro Domo Mea", Los problemas de la Universidad. Artículos y conferencias, México, SPAUNAM, 1975; en Homenaje a W. Roces por Andrea Sánchez Quintanar, "Español renacido mexicano", en coloquio La Historia de la Filosofía en México. Siglo XX. Cincuenta años de exilio español de 1939. La Filosofía. Universidad Autónoma de Tlaxcala, celebrado el 25-26 de agosto de 1989. Carpeta 4, folios 52-116, "Recortes de periódico y revistas sobre Wenceslao Roces", microfilm n²833. siempre. Y se siente así más fiel a su tierra que nunca, más que nadie, más que los demás. Pues que la comparación se va apoderando de su mente y del inagotable cálculo que podríamos llamar "existencial".

Y mientras, el desterrado mira, sueña con los ojos abiertos, se ha quedado atónito sin llanto y sin palabra, como en estado de pasmo. Y si atiende a su oficio, sea el mismo o diferente de aquel que tenía, no le saca de esa mudez, aunque para cumplirlo haya de hablar. Ningún quehacer le hace salir de ese estado en que todo se ve fijo, nítido, presente, más sin relación. ${ }^{13}$

Ahora bien, para discernir los usos del apelativo refugiado en la construcción de identidades colectivas durante y después de la Guerra Civil Española, en tanto una verdadera $c a$ tegoría del ser $^{14}$ que trasciende sus límites como mero término legal, se debe tomar en cuenta la construcción misma de dicha categoría, así como que "los términos «exiliado", «emigrado político» o «refugiado»

13 Zambrano, María, Los Bienaventurados, Madrid, Siruela, 1990, p. 37.

14 Entendiendo a las categorías del ser como los conceptos fundamentales que presentan y representan las propiedades más generales de las cosas dentro de los conceptos universales en los que se clasifican los seres ontológicamente.

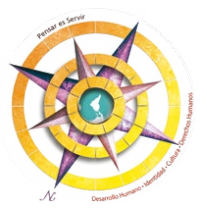


tienden a confundirse y a utilizarse como sinónimos."15

Sin embargo, pronto surge el primer problema para el análisis: la propia definición del término refugiado es elusiva. Históricamente, se ha considerado que los grandes éxodos del siglo XX iniciaron con las guerras balcánicas en 1912 y se acentuaron durante la Primera Guerra Mundial $\mathrm{y}$, sobre todo, con la Revolución Rusa de $1917 .{ }^{\mathbf{1 6}}$ A partir de este momento, el problema de los refugiados en Europa tomó tal magnitud que sobrepasó las capacidades de las organizaciones humanitarias, como la Cruz Roja, y obligó a la Sociedad de Naciones a tomar medidas al respecto, por lo que, durante el periodo de entreguerras, se implementaron diversas estrategias para aliviar el problema y proveer a los refugiados $-\mathrm{y}$ a los apátridas- de un estatus legal, documentación válida y asistencia. ${ }^{17}$ En este momento comenzó

15 Alted, Alicia, La voz de los vencidos, Santillana Ediciones, Madrid, 2005, p. 24.

16 Cf. Javier Cervera Gil: "Su segunda posguerra. Los refugiados republicanos en el sur de Francia", en Espacio, Tiempo y Forma, Serie V, Historia Contemporánea, t. 11, 1998, pp. 193-194.

17 Algunas de estas medidas fueron la creación del pasaporte Nansen (1921), la creación de la Oficina Internacional Nansen para los Refugiados (1930), la Convención Internacional de Ginebra y la creación de un Alto Comisionado para los refugiados que procedían de Alemania en 1933, entre otras. Cf. Ídem. Véase también: un largo y tortuoso proceso que buscaba definir quién podía o debía ser considerado un "refugiado" en una Europa en crisis y reconfiguración geopolítica.

En otras palabras, durante las primeras décadas del siglo $\mathrm{XX}$, y frente a una situación de emergencia, la Sociedad de Naciones buscó crear sistemas públicos para el bienestar de la población civil, pero las actividades de la gubernamentalidad global clasificaron a las diversas comunidades de refugiados como una "población" sujeta a políticas particulares según las coyunturas específicas que fueron modificando la noción del Estado-Nación en general; ello devino en la creación de una "tecnología de poder" que, en aras de la seguridad y el equilibrio global, buscaba acotar y controlar el desplazamiento.18

Para la década de los treinta, con el ascenso al poder de Hitler y Mussolini, el número de desplazados en Europa había vuelto a incrementarse y la comunidad internacional previó, de cara a un inminente nuevo conflicto armado, un desenlace similar

Namihas, Sandra (coord.), Derecho Internacional de los refugiados, Pontificia Universidad Católica del Perú-ACNUR, Lima, 2001.

18 Mi análisis de esta situación lo hago a partir de las ideas de Michel Foucault sobre seguridad, población y gubernamentalidad. Cf. Foucault, Michel, Seguridad, territorio, población, FCE, Buenos Aires, 2007. 
al de la Primera Guerra Mundial; por lo que, en julio de 1938 se celebró la Conferencia Internacional de Evian, en la que se adoptó, por primera vez, un criterio universal para definir el estatus de refugiado a partir del "temor a la persecución", criterio aún vigente y constantemente cuestionado. ${ }^{19}$

En este sentido, sorprende comprobar que mucho de lo que ha sido el desarrollo de las políticas internacionales de refugiados se da por sentado: a partir de la implementación de la Convención sobre el Estatuto de los Refugiados de 1951, pareciera que siempre hemos vivido en un mundo con un "régimen de refugiados" bien delimitado. Sin embargo, como señalé líneas arriba, la realidad es mucho más compleja: la mayor parte de las medidas que hoy damos por sentadas se delimitaron a partir de experiencias europeas de la primera mitad del s. XX y, dichas medidas surgieron, en la mayoría de los casos, como políticas ad hoc para tratar casos concretos en países en situación de emergencia. ${ }^{20}$

19 Cf. Alted, Alicia, op. cit., pp. 26-29.

20 Para una definición del concepto "régimen de refugiados" véase: Laura Barnett: "Global Governance and theevolution of the International refugeeregime", en International Journal of refugeelaw, Vol. 14, No. 2 y 3, 1 de abril de 2002, pp. 238-262.
Sin embargo, casi al margen de la configuración internacional del llamado "régimen de refugiados", la Segunda República Española implementó una política de refugiados patentemente progresista y eficiente, sobre todo considerando las propias circunstancias del conflicto bélico que atravesaba España. ${ }^{21}$ Desde el punto de vista de la construcción de un estatus legal para los refugiados, la normativa republicana procuró fijar el concepto de refugiado desde el inicio de la guerra, con la elaboración de la primera definición legal, publicada en la Gaceta de Madrid N. ${ }^{\circ} 288$ en octubre de 1936 . Esta definición tenía como propósito extender la jurisdicción del recién creado Comité de Refugiados para Madrid y su provincia:

... todos los refugiados y emigrados [que procedan de los pueblos enclavados en zonas ocupadas por los rebeldes] que no sean hostiles al régimen [republicano], carezcan de medios de vida, no estén acogidos por personas de su familia o amistad y hayan salido del lugar de su residencia

21 Se ha argumentado que "uno de los problemas más graves que tuvo que resolver el Gobierno Republicano durante la guerra fue el de la evacuación de la población civil [ ].” Rosaliacrego Navarro: "Las colonias escolares durante la Guerra Civil. (1936-1939)", en Espacio, Tiempo y Forma, Serie V, Historia Contemporánea, t. 2, 1989, p. 299.

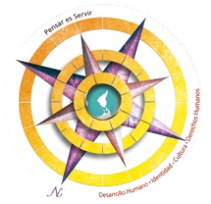


con permiso de la Autoridad civil o local o de la militar competente, teniendo derecho preferente, para la asistencia social que ha de prestárseles, las mujeres, niños, ancianos y enfermos. ${ }^{22}$

Más adelante, en marzo de 1937, se fijó la definición legal definitiva del término, que consideraba refugiado a "toda persona que, sin ser combatiente o varón sano, mayor de veinte años y menor de cuarenta y cinco, haya tenido que mudar de residencia por causa de la presente guerra, no sea hostil al régimen [republicano], carezca de medios de subsistencia y no esté acogida por otra de su familia y amistad". 23

Siguiendo la discusión que hace Partha Chatterjee de las ideas de Benedict Anderson, se puede decir que la forma de actuar del gobierno de la República Española respondió a un entendimiento utópico del espacio-tiempo moderno: se optó por aplicar principios y convicciones políticas dentro de un imaginario de comunidad con una serialidad abierta de los universales cotidianos del pensamiento social. Las serialidades abiertas suelen ser narradas de tal forma que permiten que las

22 Cf. Gaceta de Madrid (GM), N. ${ }^{\circ} 288,14-10-$ 36, pág. 328.

23 Cf. Gaceta de la República (GR), N. ${ }^{\circ}$ 62, 3-337, pág. 1.051 . personas se imaginen a sí mismas como miembros de solidaridades más amplias y les ofrecen la oportunidad de elegir actuar en nombre de estas solidaridades y de trascender, por un acto de imaginación política, los límites impuestos por las prácticas tradicionales. ${ }^{\mathbf{2 4}}$

En este sentido, podemos afirmar que las medidas de evacuación y desplazamiento, interno y externo, que implementó el gobierno de la República Española durante la guerra, fueron una excepción a la construcción internacional de la categoría refugiado que estaba teniendo lugar en la década de los treinta en la Europa de entreguerras.

Además, la importancia de reflexionar sobre la creación de estas categorías del sujeto, de la mano de sus usos como prácticas discursivas, debe enmarcarse en la crítica al esencialismo, pues:

24 Cf. Partha Chatterjee: "La política de los gobernados", en Revista Colombiana de Antropología, Vol. 47 (2), julio-diciembre, 2011. Chatterjee hace una crítica de la obra de Benedict Anderson TheSpectre of Comparison, en el que Anderson hace una diferenciación entre el nacionalismo y la política de la entincidad. Mi intención al usar estas nociones no es ahondar en el discusión sobre la política de la etnicidad, sino "salvando las distancias" aplicar la discusión, en términos de gobernanza, a la manera como la República Española optó por gobernar en un momento dado. 
los entes históricos, cualesquiera que sean, no son lo que son en virtud de una supuesta esencia o sustancia que haría que sean lo que son. Con otras palabras, su ser no les es inherente, no es sino el sentido que les concede el historiador en una circunstancia dada o más claramente dicho, en el contexto del sistema de ideas y creencias en que vive. ... El ser, pues, de un ente histórico es mudable y mudable será, correlativamente, su historia ...."25

En este sentido cabe preguntarnos qué características tuvieron las memorias de la guerra para la construcción identitaria colectiva del exilio republicano español en México:

Si seguimos el recorrido identitario propuesto por Sánchez Vázquez, según el cual, en un primer momento, el exiliado se encuentra aterrado en el más profundo sentido del término: perdido, sin tierra, despavorido, resulta comprensible que éste se aferre a sus recuerdos. Su única forma de sobrevivir es recordar, pues es la única forma con la que puede insertar cierta coherencia a sus circunstancias y mantener consciencia de sí mismo. En este momento la memoria es una compulsión, una afección, es pathos. ${ }^{\mathbf{2 6}}$

Con el tiempo, esta afección se tornaría en un compromiso político. ${ }^{27}$ Es en este momento cuando "la recuperación del pasado se manifiesta como una voluntad irreprimible de afirmar la existencia histórica, no sólo la individual, sino también la de la comunidad". ${ }^{28}$

Dentro del ámbito del recuerdo individual, existe un gran número de testimonios, novelas y poesía publicadas, que narran las experiencias individuales de sus autores $-\mathrm{O}$ de los padres o abuelos de sus autores-. Estos recuerdos individuales respondieron, necesariamente, a urgencias individuales por narrar la propia historia. Pero estas historias individuales son también la historia colectiva, de ahí que la urgencia no sea solo escribir memorias, sino también leerlas. Así, por ejemplo, en el prólogo a Éxodo. Diario de una refugiada española, de Silvia Mistral, editado por primera vez en 1940, León Felipe escribió: "Hay que escribir esta historia y hay que leerla con valor y con frecuencia para que estén ahí

26 Acevedo López, Guiomar, op. cit., p. 83.

27 Cf. Ibídem, p. 84.

28 Clara Lida, op. cit., 2004, p. 311.

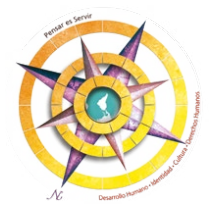


siempre, ante nuestros ojos, nuestras miserias y nuestros pecados." 29

Desde el punto de vista de la memoria de la comunidad, la memoria se convierte en un acuerdo colectivo pactado a partir de lugares comunes - colegios, centros culturales, etc. - , los cuales se convierten en el epicentro de la vida colectiva. ${ }^{30}$

A esto se debe sumar que "conocerse a sí mismo es hacer memoria de lo que se ha sido, hacer recuento de lo que se es e imaginar lo que se quiere ser. Esto es, reconocerse en la historia misma de la propia existencia y en el propósito estimado de la misma."31

Así pues, quizá el continuado uso coloquial del apelativo refugiado a lo largo de décadas tenga los matices de una expresión de la memoria: como veíamos en Sánchez Vázquez, el carácter reflexivo sobre la condición del exilio fue un tema recurrente en la literatura -testimonial o ensayística- del exilio republicano español en México y, por su parte, la categoría refugiado, como hemos visto, permitió la gesta de un "fenómeno cultural del nosotros frente a los otros; el cual devino en un

29 Mistral, Silvia, Éxodo. Diario de una refugiada española, Icaria, Madrid, 2011, p. 69.

30 Cf. Guiomar Acevedo, op. cit., p. 80.

31 Ibidem, p. 82. sentido de cohesión que gestó una identidad común muy especial, posiblemente sin parangón. Esta noción de otredad poco tenía que ver con una confrontación con lo mexicano, pues como grupo, los exiliados republicanos siempre se caracterizaron por un profundo respeto y gratitud hacia la solidaridad que México les había ofrecido." ${ }^{32}$ No, el otro no era el mexicano, era, como habíamos dicho, el gachupín; e, incluso, el fascista.

En este sentido, Peter Burke nos advierte:

A menudo se dice que la historia la escriben los vencedores. También podría decirse que la olvidan los vencedores. Ellos pueden permitirse olvidar, mientras que los derrotados no pueden olvidar lo que ocurrió y están condenados a cavilar sobre ello, a revivirlo y a pensar en lo diferente que habría podido ser. ${ }^{33}$

La vasta producción cultural que caracterizó al exilio republicano español, particularmente fecunda en el ámbito literario, representa un testimonio indeleble que hizo posible la perduración de la memoria del exilio y su transmisión intergeneracional.

32 Ibidem, p. 79-80.

33 Peter Burke, "La historia como memoria colectiva", en Formas de historia cultural, Alianza, Madrid, 1999, pág. 79. 
Dicho en otras palabras, la obra reflexiva que el exilio produjo supone uno de los procesos de conservación de la memoria del propio exilio, pues: "Escribir y recordar - o recordar a través de la escritura- ayudan ... a superar la miserable amnesia que ha sido usada para sobrellevar al sentimiento de exilio, a la exclusión y a la perdida de los lugares queridos." 34

A partir de todo lo anterior, podemos concluir que la producción de memorias (particularmente en tanto que producción literaria, testimonial y ensayística) del exilio republicano español en México, se vincula estrechamente con los recuerdos de la Guerra Civil, más no de manera explícita, pues la guerra figura siempre de forma más bien velada en dichos testimonios, sino como origen del ethos del colectivo de "refugiados españoles" en México, en tanto que sentimiento común de pertenencia a una comunidad.

\section{Bibliografía}

Acevedo López, Guiomar. (2011). Entre memoria y olvido: Ochenta años del pasado contemporáneo español. Limusa-Morados.

ACNUR. (2012). La situación de los refugiados en el mundo. En busca de la solidaridad. Representación de ACNUR en España.

A.G.G.C. (1975). Wenceslao Roces: "Pro Domo Mea", Los problemas de la Universidad. Artículos y conferencias, México, SPAUNAM, 1975. En Homenaje a W. Roces por Andrea Sánchez Quintanar, "Español renacido mexicano", en coloquio La Historia de la Filosofía en México. Siglo $X X$. Cincuenta años de exilio español de 1939. La Filosofía. Universidad Autónoma de Tlaxcala, celebrado el 25-26 de agosto de 1989. Carpeta 4, folios 52-116, "Recortes de periódico y revistas sobre Wenceslao Roces", microfilm $n^{\circ} 2833$.

Anderson, Linda. (2007). Diaspora: Introduction. En Rossington, Michael y Anne Whitehead (Eds.), Theories of Memory. A Reader. Johns Hopkins University Press, Baltimor.

Alted, Alicia. (2005). La voz de los vencidos. Santillana Ediciones.

Álvarez Arregui, Federico. (2007). Discurso de D. Federico Álvarez Arregui. En M. D. Gutiérrez Navas (Ed.), Homenaje a Adolfo Sánchez Vázquez. FCE-Junta de Andalucía, Conserjería de la Cultura, Madrid.

Barnett, Laura. (2002, abril). Global Governance and the Evolution of the International Refugee Regime. International Journal of Refugee Law, $14(2$ y 3$)$.

Burke, Peter. (1999). La historia como memoria colectiva. En Formas de historia cultura. Alianza.

34 Cf. Linda Anderson,op. cit., p. 274. 
Cervera Gil, Javier. (1998). Su segunda posguerra. Los refugiados republicanos en el sur de Francia. En Espacio, Tiempo y Forma, Serie V, Historia Contemporánea, t. 11.

Chatterjee, Partha. (2011, julio-diciembre). La política de los gobernados. Revista Colombiana de Antropología, 47(2).

Climent Beltrán, Juan Bautista. (1992). Crónicas de Valencia. Escritos desde el exilio, Generalitat Valenciana, Conselleria de Cultura, Educació i Ciéncia.

Crego Navarro, Rosalia. (1989). Las colonias escolares durante la Guerra Civil (1936-1939). En Espacio, Tiempo y Forma, Serie V, Historia Contemporánea, t. 2, p. 299.

Dávila Valdés, Claudia. (2007). El tratamiento jurídico-administrativo a los refugiados de la guerra civil española en Francia y México: Un estudio comparativo. Secuencia, 69, 2007.

Elie, Jérôme. (2014). Histories of Refugee and Forced Migration Studies. En Fiddian-Qasmiyeh, Elena, et al (Eds.), The Oxford Handbook of Refugee and Forced Migration Studies. Oxford University Press.

Foucault, Michel. (1984). El juego de Michel Foucault. En Saber y verdad. Ediciones de la Piqueta.

Foucault, Michel. (2007). Seguridad, territorio, población. FCE.

Gaceta de la República (GR), N. ${ }^{\circ} 62$ y 240.

Gaceta de Madrid (GM), N. ${ }^{\circ} 288$.
Guarner, Vicente. (1982). Los exiliados españoles del 39 y el México de ahora. En El exilio español en México, 1939-1982. FCE, Salvat.

Lida, Clara. (2004). Voluntad de Memoria. Los exilios hispánicos en México en siglo XX. En Actas XIV Congreso Asociación Internacional de Hispanistas: Nueva York 16-21 julio 2001 (Vol. I).

Lida, Clara. (1997). Inmigración y exilio. Reflexiones sobre el caso español. Siglo XXI; El Colegio de México.

Mistral, Silvia. (2011). Éxodo. Diario de una refugiada española. Icaria.

Namihas, Sandra (coord.). (2001). Derecho Internacional de los refugiados, Pontificia Universidad $\mathrm{C}$ a tólica del Perú-ACNUR.

O'Gorman, Edmundo. (1995). Fantasmas en la narrativa historiográfica. Historia y Grafía, No. 5.

Sánchez, A. (1997). Del exilio en México. Recuerdos y reflexiones. Grijalbo, México.

Tirado, A. (2007). La política exterior del México cardenista hacia la Segunda República Española. El caso del exilio republicano en México: ¿Cooperación ideológica o interés pragmático? [Tesis doctoral]. Universidad Autónoma de Barcelona.

Zambrano, M. (1990). Los bienaventurados. Siruela. 